\title{
Antidepressant prophylaxis reduces depression risk but does not improve sustained virological response in hepatitis $C$ patients receiving interferon without depression at baseline: A systematic review and meta-analysis
}

\author{
Awad Al-Omari MD ${ }^{1}$, Juthaporn Cowan MD ${ }^{1}$, Lucy Turner BSc MSc ${ }^{2}$, Curtis Cooper MD FRCPC ${ }^{1,2}$
}

\begin{abstract}
A Al-Omari, J Cowan, L Turner, C Cooper. Antidepressant prophylaxis reduces depression risk but does not improve sustained virological response in hepatitis $\mathrm{C}$ patients receiving interferon without depression at baseline: A systematic review and meta-analysis. Can J Gastroenterol 2013;27(10):575-581.
\end{abstract}

BACKGROUND: Depression complicates interferon-based hepatitis C virus (HCV) antiviral therapy in $10 \%$ to $40 \%$ of cases, and diminishes patient well-being and ability to complete a full course of therapy. As a consequence, the likelihood of achieving a sustained virological response (SVR [ie, permanent viral eradication]) is reduced.

OBJECTIVE: To systematically review the evidence of whether preemptive antidepressant prophylaxis started before HCV antiviral initiation is beneficial.

METHODS: Inclusion was restricted to randomized controlled trials in which prophylactic antidepressant therapy was started at least two weeks before the initiation of HCV antiviral treatment. Studies pertaining to patients with active or recent depressive symptoms before commencing HCV antiviral therapy were excluded. English language articles from 1946 to July 2012 were included. The MEDLINE, Embase and Cochrane Central databases were searched. Where possible, meta-analyses were conducted evaluating the effect of antidepressant prophylaxis on SVR and major depression as well as on Montgomery-Asberg Depression Rating Scale and Beck Depression Index scores at four, 12 and 24 weeks. The Cochrane Collaboration tool was used to assess bias risk.

RESULTS: Six randomized clinical trials involving 522 patients met the inclusion criteria. Although the frequency of on-treatment clinical depression was decreased with antidepressant prophylaxis (risk ratio 0.60 [ $95 \%$ CI 0.38 to 0.93 ]; $\mathrm{P}=0.02 ; \mathrm{I}^{2}=24 \%$ ), no benefit to SVR was identified (risk ratio 1.08 [95\% CI 0.74 to 1.57$] ; \mathrm{P}=0.69 ; \mathrm{I}^{2}=58 \%$ ).

CONCLUSION: This practice is not justified to improve SVR in populations free of active depressive symptoms leading up to $\mathrm{HCV}$ antiviral therapy.

Key Words: Antidepressant; Antiviral treatment; Depression; Hepatitis C; Prophylaxis
Les antidépresseurs en prophylaxie réduisent le risque de dépression mais n'améliorent pas la réponse virologique soutenue chez les patients atteints d'hépatite $\mathrm{C}$ qui reçoivent de l'interféron sans être déprimés au départ : une analyse systématique et une méta-analyse

HISTORIQUE : La dépression complique l'antivirothérapie à l'interféron conte le virus de l'hépatite $\mathrm{C}$ (VHC) chez $10 \%$ à $40 \%$ des patients et réduit leur bien-être et leur capacité de terminer le traitement. Par conséquent, la probabilité d'obtenir une réponse virologique soutenue (RVS [c.-à-d. une éradication virale permanente]) est réduite.

OBJECTIF : Procéder à l'analyse systématique des données probantes pour déterminer si une prophylaxie préventive aux antidépresseurs amorcée avant le début du traitement antiviral du VHC est bénéfique.

MÉTHODOLOGIE : L'inclusion était limitée aux essais aléatoires et contrôlés où on avait commencé à donner les antidépresseurs en prophylaxie au moins deux semaine avant le début du traitement antiviral contre le VHC. Les études sur les patients qui présentaient des symptômes de dépression actifs ou récents avant le début de l'antivirothérapie contre le VHC étaient exclues. Les articles en anglais publiés entre 1946 et juillet 2012 étaient inclus dans l'étude. Les auteurs ont fouillé les bases de données MEDLINE, Embase et Cochrane Central. Dans la mesure du possible, ils ont effectué des méta-analyses sur l'effet de la prophylaxie aux antidépresseurs sur la RVS et la dépression majeure ainsi que sur l'échelle d'évaluation de la dépression de Montgomery-Asberg et sur les indices de dépression de Beck au bout de quatre, 12 et 24 semaines. Ils ont utilisé l'outil de la Collaboration Cochrane pour évaluer le risque de biais.

RÉSULTATS : Six essais aléatoires cliniques auprès de 522 patients respectaient les critères d'inclusion. Même si la fréquence de dépression clinique pendant le traitement était réduite grâce à la prophylaxie aux antidépresseurs, (risque relatif de 0,60 [95 \% IC 0,38 à 0,93]; P=0,02; $\mathrm{I}^{2}=24 \%$ ), la RVS ne s'associait à aucun avantage perçu (risque de de 1,08 [95 \% IC 0,74 à 1,57]; P=0,69; $\mathrm{I}^{2}=58 \%$ ).

CONCLUSION : Cette pratique n'est pas justifiée pour améliorer la RVS au sein de la population sans symptômes de dépression active avant une antivirothérapie contre le VHC.

cases, antidepressants are required, mental health services provided, IFN doses reduced and/or antiviral therapy interrupted.

Antidepressants are a mainstay for treating depression associated with IFN- $\alpha$-based HCV therapy $(6,13)$. Multiple studies have reported success in retaining patients on HCV antiviral therapy with the use of antidepressants in the management of IFN-induced depression $(14,15)$. However, it remains unclear as to whether this practice benefits SVR rates $(10,16,17)$.

An alternative approach to the management of IFN-induced depression is the use of antidepressant prophylaxis started before or at the time of HCV antiviral initiation. Several studies have attempted interferon-alpha $(\mathrm{IFN}-\alpha)$ is major depression $(7,8)$. The risk has been reported to range between $10 \%$ and $40 \%(4,5,9-12)$. In many

${ }^{1}$ University of Ottawa, Division of Infectious Diseases; ${ }^{2}$ Ottawa Hospital Research Institute, Ottawa, Ontario

Correspondence: Dr Curtis Cooper, The Ottawa Hospital, Division of Infectious Diseases, G12-501 Smyth Road, Ottawa, Ontario K1H 8L6.

Telephone 613-737-8924,fax 613-737-8164,e-mail ccooper@toh.on.ca

Received for publication May 15, 2013. Accepted June 21, 2013 
to address the effectiveness of this strategy without clearly resolving the issue $(1,18-22)$. To address this unresolved question, we conducted a meta-analysis on the use of prophylactic antidepressants in patients initiating IFN-based HCV antiviral treatment. The impact on virological response, SVR rates and measures of mental health status were specifically addressed.

\section{METHODS}

\section{Search strategy}

A review protocol and search strategy was developed to capture articles describing HCV antiviral treatment in which prophylactic antidepressant therapy was used. English language articles from 1946 to July 2012 were included. The MEDLINE, Embase and Cochrane Central databases were searched. Reference lists of selected articles were also screened for eligible reports. The search strategies used are presented in Appendix 1.

\section{Eligibility criteria}

Inclusion was restricted to randomized controlled trials (RCTs) in which prophylactic antidepressant therapy was started at least two weeks before the initiation of HCV antiviral treatment.

\section{Study selection and data extraction}

All titles and abstracts of the citations identified by the literature search were independently screened by two investigators (AA-O and $\mathrm{CC}$ ). Relevant articles were reviewed in their entirety. Each investigator made a recommendation for inclusion or exclusion of single articles and, if discordant, a third investigator (JC) resolved the discrepancy. When two or more articles had overlap of their populations and reported on the same outcomes, only the most inclusive article was considered with supplementary information taken from the overlapping articles.

Using a standardized form, two investigators (AA-O and JC) systematically collected data on the outcomes of interest, population characteristics and several aspects of study setting and methodological design. Virological response to treatment (ie, SVR) and major depression were specifially addressed. The Montgomery-Asberg Depression Rating Scale (MADRS) and Beck Depression Index (BDI) were also evaluated. The MADRS is a 10 -item, clinician-administered measure of current depressive symptoms. It provides a measure of depressive symptomatology in patients with chronic medical conditions that is less influenced by physical symptoms and more sensitive to changes in depressive symptoms. The BDI, Second Edition, is a 21-item, self-reported tool used to evaluate depression symptom severity that is well validated and reliable in HCV patients and in IFN recipients (23-25).

Individual studies were assessed using the Cochrane Collaboration's tool for assessing risk of bias in randomized trials by two investigators (AA-O and JC) (26). Reporting of the following individual components were assessed: description and method of generation of the randomization sequence; method of allocation concealment; method of blinding; report of incomplete outcome data; selective reporting bias; and other biases such as baseline imbalance or early termination due to some data-dependent process.

\section{Synthesis and meta-analysis}

Where possible, measures of effect were pooled using standard metaanalysis methods. Pooled risk ratios (RR) and mean differences (MD) with associated $95 \%$ CIs were for calculated for dichotomous and continuous outcomes, respectively. Studies were pooled using randomeffects models by the generic inverse variance method (27). However, where homogeneity allowed, both fixed- and random-effects results were calculated. Where studies reported medians, effect distribution was assessed and variance estimates were calculated using standard methods (28). Clinical and methodological heterogeneity was investigated and sensitivity analyses performed where necessary. Statistical heterogeneity was measured using the $\mathrm{I}^{2}$ statistic (29); all meta-analyses were conducted irrespective of statistical heterogeneity. No subgroup analyses were performed. Study outcomes not eligible for inclusion in meta-analyses were reported descriptively across studies.

\section{RESULTS}

A total of 400 potentially eligible trials were retrieved through electronic searches; 310 nonduplicate publications were identified (Appendix 1). Twenty-one full-text articles were reviewed, of which 15 were excluded as companion studies or nonrandomized trials. In total, six RCTs met the inclusion criteria and were included in the meta-analysis (Table 1, Figure 1). Antidepressants evaluated included paroxetine $(n=2[20,21])$ escitalopram $(n=3[1,18,22])$ and citalopram $(n=1$ [19]). The period of time required to be free of ongoing depression or psychiatric symptoms ranged from two to six months. All but one study (1) excluded patients with past or current mood disorders, bipolar and psychotic psychiatric conditions. All studies excluded individuals with active substance abuse. The time to randomization before HCV antiviral treatment initiation ranged from zero to four weeks. Some studies used dose escalation and intensification strategies while others used a single, fixed dose. Four of six studies administered antidepressants for the entire duration of HCV antiviral therapy. The exceptions included the Diez-Quevedo et al (18) evaluation, in which patients were randomly assigned to escitalopram or placebo for the initial 12 weeks of treatment, and the de Knegt et al (1) assessment, in which citalopram was dosed for 26 weeks. All study participants received one of several IFN formulations administered subcutaneously and daily oral ribavirin. The targeted duration of HCV antiviral therapy was consistent across studies: 48 weeks for genotypes 1 and 4 , and 24 weeks for genotypes 2 and 3 .

\section{Risk of bias in included studies}

An assessment of each study against the individual methodological quality criteria described in the method section is provided in the table of risk of bias summary (Appendix 2). All studies were reported as 'randomized', although one article (20) did not describe the method of randomization. There is only one study that had low risk of bias across all domains. The study by Morasco et al (19) did not address incomplete outcome data and the study code was broken to several patients in the de Knegt et al (1) article. The study by Schaefer et al (22) had a baseline imbalance at the time of randomization in which baseline MADRS was higher in the placebo group even though this score normalized at the time of study. Overall, the included trials were assessed to be of reasonable quality.

SVR rate was not improved by prophylactic antidepressant use Four studies including 382 patients reported SVR rates (18-20,22) (Table 2).The pooled estimate of effect resulted in no statistical difference in SVR rate between recipients of prophylactic antidepressants and the placebo group (RR 1.08 [95\% CI 0.74 to 1.57]; $\mathrm{P}=0.69$; $\mathrm{I}^{2}=58 \%$ ) (Figure 2).

\section{Prophylactic antidepressant therapy protected against clinical depression}

All studies reported information describing the proportion of patients who developed clinical depression during the study period and/or at the end of the trial (Table 2). DSM-IV criteria were used to identify patients with clinical depression in four studies (18-21). The MiniInternational Neuropsychiatry Interview (MINI) was used to diagnose depression in one study (1). A score of $\geq 13$ on the MADRS was considered to be clinical depression in one study (22). The percentage of clinical depression was $10.51 \%$ (27 of 257) in the treatment group and $18.49 \%$ (49 of 265) in the placebo group (RR 0.60 [95\% CI 0.38 to 0.93]; $\mathrm{P}=0.02 ; \mathrm{I}^{2}=24 \%$ ) (Figure $3 \mathrm{~A}$ ). The same analysis was conducted excluding a directional outlier with similar results (Figure 3B).

Psychiatric assessment scores used to grade depression severity did not differ between treatment and the control groups

Most studies reported MADRS results at four, 12 and 24 weeks 
TABLE 1

Baseline characteristics

\begin{tabular}{|c|c|c|c|c|c|c|c|c|c|}
\hline $\begin{array}{l}\text { Author } \\
\text { (reference), } \\
\text { year }\end{array}$ & Group & $\begin{array}{c}\text { Cases, } \\
\mathbf{n}\end{array}$ & $\begin{array}{c}\text { Age, } \\
\text { years* }\end{array}$ & $\begin{array}{c}\text { Sex, } \\
M: F, \%\end{array}$ & $\begin{array}{c}\text { HCV } \\
\text { genotype: \% }\end{array}$ & $\begin{array}{c}\text { Duration of } \\
\text { HCV antiviral } \\
\text { treatment }\end{array}$ & $\begin{array}{l}\text { History of } \\
\text { psychiatric } \\
\text { illness, \% }\end{array}$ & $\begin{array}{c}\text { Psychiatic scoring } \\
\text { (at baseline) }\end{array}$ & Antidepressant prophylaxis \\
\hline \multirow{4}{*}{$\begin{array}{l}\text { Raison et al } \\
(21), 2007\end{array}$} & Treatment & 28 & $51.1 \pm 6.5$ & $53.6: 46.4$ & NA & 24 weeks & MD, 25 & MADRS $=3.5 \pm 3.6^{\dagger}$ & Paroxetine up to $40 \mathrm{mg} /$ day \\
\hline & & & & & & & SA, 64 & MADRS $=3.5^{\ddagger}$ & 2 weeks before antiviral treatment \\
\hline & Placebo & 33 & $46.6 \pm 8.2$ & $60.6: 39.4$ & NA & & MD, 24 & MADRS $=5.2 \pm 5.2^{\dagger}$ & \\
\hline & & & & & & & SA, 64 & MADRS $=3.0^{\star \star}$ & \\
\hline \multirow{4}{*}{$\begin{array}{l}\text { Morasco } \\
\text { et al (20), } \\
2007\end{array}$} & Treatment & 14 & $50.6 \pm 5.4$ & $100: 0$ & 1: 76.9 & G1, 48 weeks & MD, 14.3 & HAM-D $=2.9 \pm 5.6^{\dagger}$ & Paroxetine up to 40 mg/day \\
\hline & & & & & $2+3: 23.1$ & $\mathrm{G} 2 / 3,24$ weeks & ETOH, 85.7 & $\mathrm{HAM}-\mathrm{A}=4.0 \pm 6.9^{\dagger}$ & 4 weeks before antiviral treatment \\
\hline & Placebo & 19 & $46.4 \pm 4.9$ & $100: 0$ & $1: 73.7$ & & MD, 15.8 & $\mathrm{HAM}-\mathrm{D}=1.8 \pm 3.3^{\dagger}$ & \\
\hline & & & & & $2+3: 26.3$ & & ETOH, 68.4 & $\mathrm{HAM}-\mathrm{A}=1.5 \pm 2.5^{\dagger}$ & \\
\hline \multirow{4}{*}{$\begin{array}{l}\text { Morasco } \\
\text { et al (19), } \\
2010\end{array}$} & Treatment & 19 & 51.8 & $94: 6$ & $1: 63.2$ & Physician & MD, 10.5 & MADRS $=3.8 \pm 4.2^{\dagger}$ & Citalopram 20 mg/day 2 weeks \\
\hline & & & & & $2+3: 36.8$ & discretion & & $\mathrm{BDI}-\mathrm{II}=3.3 \pm 3.9^{\dagger}$ & before antiviral treatment \\
\hline & Placebo & 20 & 54.2 & $90: 10$ & 1: 45 & & MD, 15 & MADRS $=3.0 \pm 3.0^{\dagger}$ & \\
\hline & & & & & $2+3: 55$ & & & $\mathrm{BDI}-\mathrm{II}=5.3 \pm 4.6^{\dagger}$ & \\
\hline \multirow{4}{*}{$\begin{array}{l}\text { de Knegt } \\
\text { et al (1), } \\
2011\end{array}$} & Treatment & 40 & $48.5 \pm 9.7$ & $67.5: 32.5$ & $1+4: 45$ & G1/4, 48 weeks & DE, 10 & MADRS $=4.58 \pm 3.9^{\dagger}$ & Escitalopram 5 mg/day for 2 weeks \\
\hline & & & & & $2+3: 55$ & $\mathrm{G} 2 / 3,24$ weeks & SA, 12.5 & $\mathrm{BAS}=0.83 \pm 1.0^{\dagger}$ & then $10 \mathrm{mg} /$ day until week 24 then \\
\hline & Placebo & 39 & $44.6 \pm 7.5$ & $89.7: 10.3$ & $1+4: 46.2$ & & $\mathrm{DE}, 25$ & MADRS $=4.69 \pm 4.7^{\dagger}$ & $5 \mathrm{mg} /$ day for 2 weeks \\
\hline & & & & & $2+3: 53.8$ & & SA, 15 & $\mathrm{BAS}=0.95 \pm 1.0^{\dagger}$ & \\
\hline \multirow{8}{*}{$\begin{array}{l}\text { Diez- } \\
\text { Quevedo } \\
\text { et al (18), } \\
2011\end{array}$} & Treatment & 66 & $46.7 \pm 10.6$ & $59.1: 40.9$ & $1: 66.7$ & Physician & MD, 13.6 & MADRS $=2.6 \pm 3.5^{\dagger}$ & Escitalopram 15 mg/day 2 weeks \\
\hline & & & & & 2: 7.6 & discretion & ETOH, 7.6 & $\mathrm{HADS}=2.5 \pm 2.8^{\dagger}$ & before antiviral treatment \\
\hline & & & & & 3: 18.2 & & & & \\
\hline & & & & & $4: 7.6$ & & & & \\
\hline & Placebo & 63 & $48 \pm 10.8$ & $63.5: 36.5$ & $1: 82.5$ & & MD, 12.7 & MADRS $=2.3 \pm 2.8^{\dagger}$ & \\
\hline & & & & & 2: 1.6 & & ЕTOH, 9.5 & $\mathrm{HADS}=2.4 \pm 2.5^{\dagger}$ & \\
\hline & & & & & 3: 12.7 & & & & \\
\hline & & & & & $4: 3.2$ & & & & \\
\hline \multirow{8}{*}{$\begin{array}{l}\text { Schaefer } \\
\text { et al (22), } \\
2012\end{array}$} & Treatment & 90 & 46.2 & $54: 46$ & 1: 60 & G1/4, 48 weeks & No previous & MADRS $=2.1 \pm 2.6^{\dagger}$ & Escitalopram 10 mg/day 2 weeks \\
\hline & & & & & $2: 10$ & G2/3, 24 weeks & psychiatric & MADRS $=1.3^{\ddagger}$ & before antiviral therapy. Stopped at \\
\hline & & & & & 3: 21 & & illnesses & & the end of antiviral therapy \\
\hline & & & & & 4: 9 & & & & \\
\hline & Placebo & 91 & 48.5 & $53: 47$ & 1: 65 & & & MADRS $=2.7 \pm 3.9^{\dagger}$ & \\
\hline & & & & & 2: 5 & & & MADRS $=1.6^{\ddagger}$ & \\
\hline & & & & & 3: 23 & & & & \\
\hline & & & & & 4: 7 & & & & \\
\hline
\end{tabular}

${ }^{\star}$ Data presented as mean \pm SD or mean. ${ }^{\dagger}$ Mean \pm SD; ${ }^{\ddagger}$ Median. BAS Brief Anxiety Scale; BDI-II Beck's Depression Inventory (2nd Edition); DE Depressive episodes; ETOH Alcohol use disorder; F Female; G Genotype; HADS Hospital Anxiety and Depression Scale; HAM-A Hamilton Anxiety Scale; HAM-D Hamilton Depression Scale; HCV Hepatitis C virus; M Male; MADRS Montgomery-Asberg Depression Rating Scale; MD Major depression; NA Not applicable; SA Substance abuse

$(1,18,19,22)$ (Figure 4A). The scores ranged from 3.97 to 9.5 in the treatment group and 4.81 to 10.92 in the placebo group. The MD in MADRS scores between treatment and placebo was -1.42 (95\% CI -3.15 to $0.31 ; \mathrm{P}=0.11) ;-1.12(95 \% \mathrm{CI}-3.61$ to $1.37 ; \mathrm{P}=0.38)$ and $-2.12(95 \% \mathrm{CI}-5.17$ to $0.094 ; \mathrm{P}=0.17$ ) at four, eight and 12 weeks, respectively. The Schaefer et al (22) study reported MD at four, 12 and 24 weeks but not absolute mean MADRS for each study group. To address this, the mean MADRS and SDs at were calculated at weeks 4, 12 and 24 based on the reported baseline MADRS score. Sensitivity analysis was conducted excluding data extracted from Schaefer et al (22) to determine whether this methodology introduced bias in estimate of effect (data not shown). The MD of MADRS score at four, 12 and 24 weeks were not significantly different using this approach. The BDI score was reported in two studies $(1,19)$. The BDI score at weeks 4, 8 and 24 did not differ between groups (Figure 4B).

\section{DISCUSSION}

Ultimately, the goal of antidepressant prophylaxis is to maintain patients on full doses of IFN and ribavirin and enable completion of the full duration of HCV antiviral therapy thereby maximizing the likelihood of achieving an SVR. Our meta-analysis, based on six RCTs with a low overall risk of bias (Appendix 2), suggests that this is not achieved, at least not in the populations evaluated. Individuals eligible for participation in these RCTs were characterized as being free from current

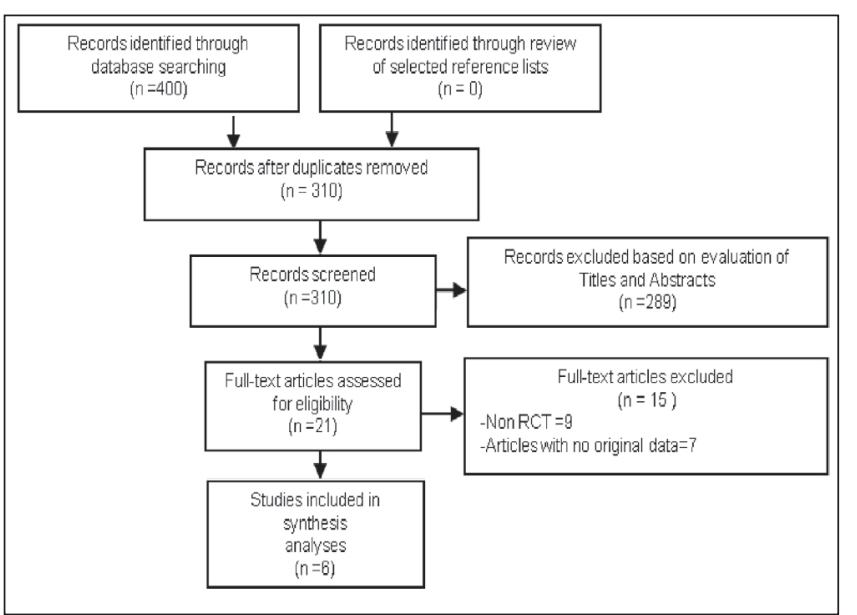

Figure 1) Flow diagram of included studies. Flow diagram of records identified by search of electronic databases (MEDLINE, Embase, Cochrane Central) and reference lists of selected studies filtered according to hepatitis $\mathrm{C}$ antiviral treatment and prophylactic antidepressant therapy. The search was limited to studies indexed between 1946 and July 2012. The electronic search strategy is detailed in Appendix 1. RCT Randomized clinical trial 
TABLE 2

Outcomes

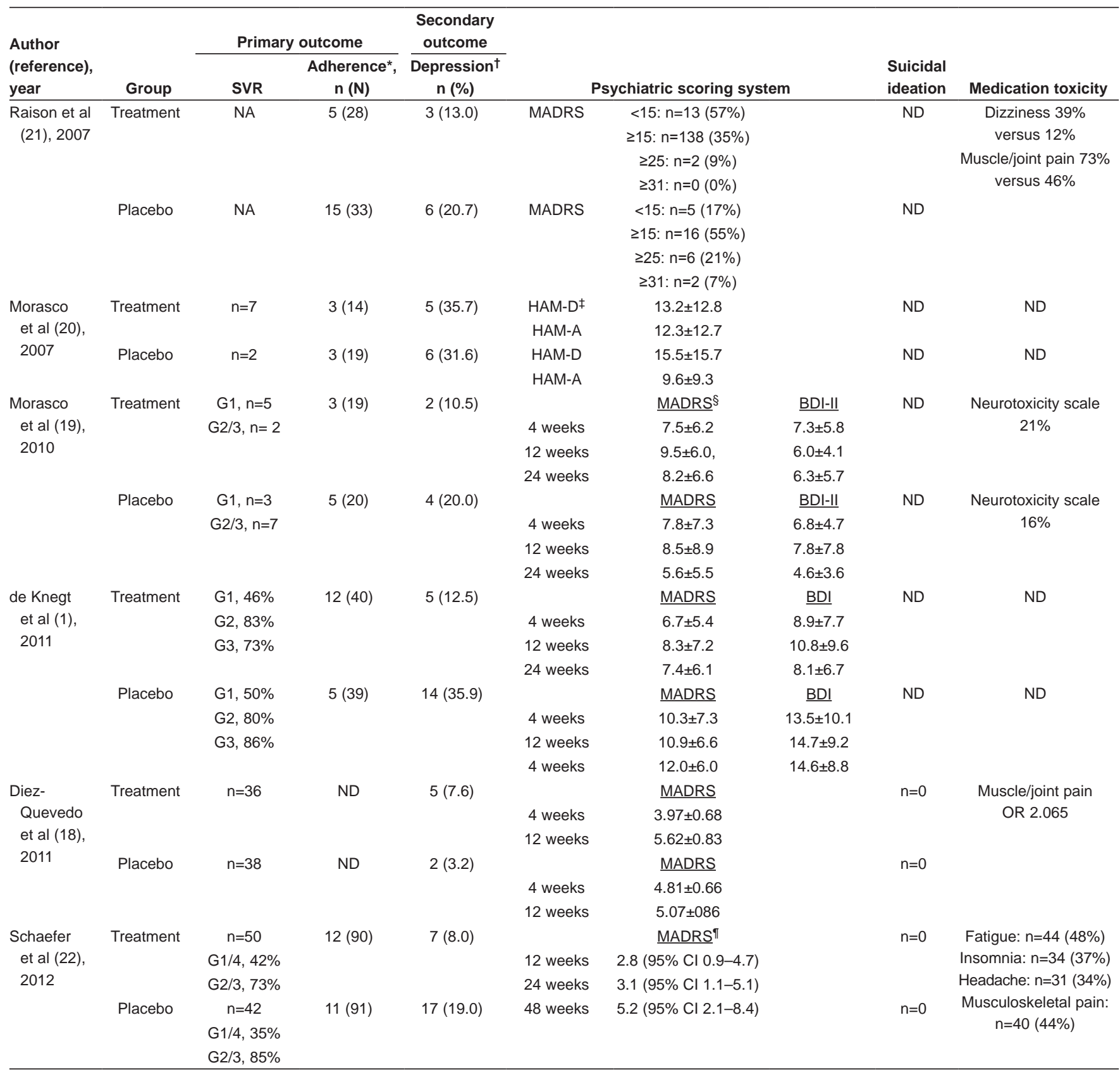

${ }^{*}$ Participants not completing treatment for hepatitis $\mathrm{C}$ virus (HCV) treatment; ${ }^{\dagger}$ Participants experiencing major depression during HCV treatment; ${ }^{\ddagger} \mathrm{HAM}-\mathrm{A}$ Hamilton Anxiety Scale; HAM-D Hamilton Depression Scale (HAM-D) score as outcome was mean highest score during treatment; ${ }^{\S}$ Author-reported mean \pm SD MontgomeryAsberg Depression Rating Scale (MADRS) score, significantly different at week 16 and 20 post-treatment; "Mean difference; BDI Beck Depression Inventory (2nd Edition); G Genotype; MINI Mini-International Neuropsychiatry Interview; ND No data

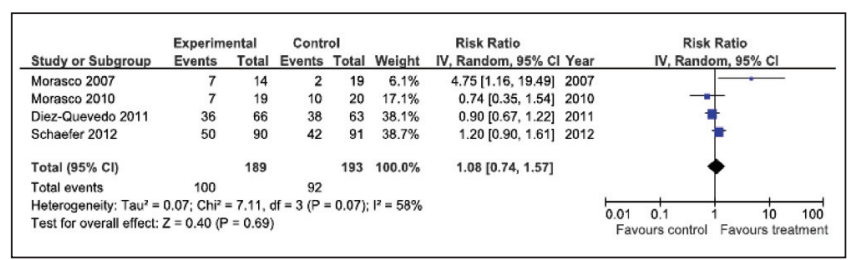

Figure 2) Sustained virological response (SVR) rate. Forest plot of the SVR rate compared between recipients of prophylactic antidepressants and the placebo group

or recent clinical depression, or other concurrent active psychiatric conditions. Furthermore, these participants were not taking any mental health medications at the time of enrollment. Our analysis established that antidepressant prophylaxis in advance of initiating HCV antiviral therapy is not beneficial in improving SVR in individuals with stable mental health. This does not resolve the question with regard to individuals with mild depression or other active psychiatric conditions planning to start HCV treatment. It is plausible that this benefit may have a more clinically significant effect in those with borderline depression or active, but stable, concurrent mental health concerns during the lead-up period to HCV therapy. Our analysis indicated that the risk for developing on-treatment depression was reduced in those randomly assigned to receive antidepressant prophylaxis, although the Diez-Quevedo et al (18) study, which has the highest internal validity or lowest risk of bias among the six trials, did not show decreased rate 


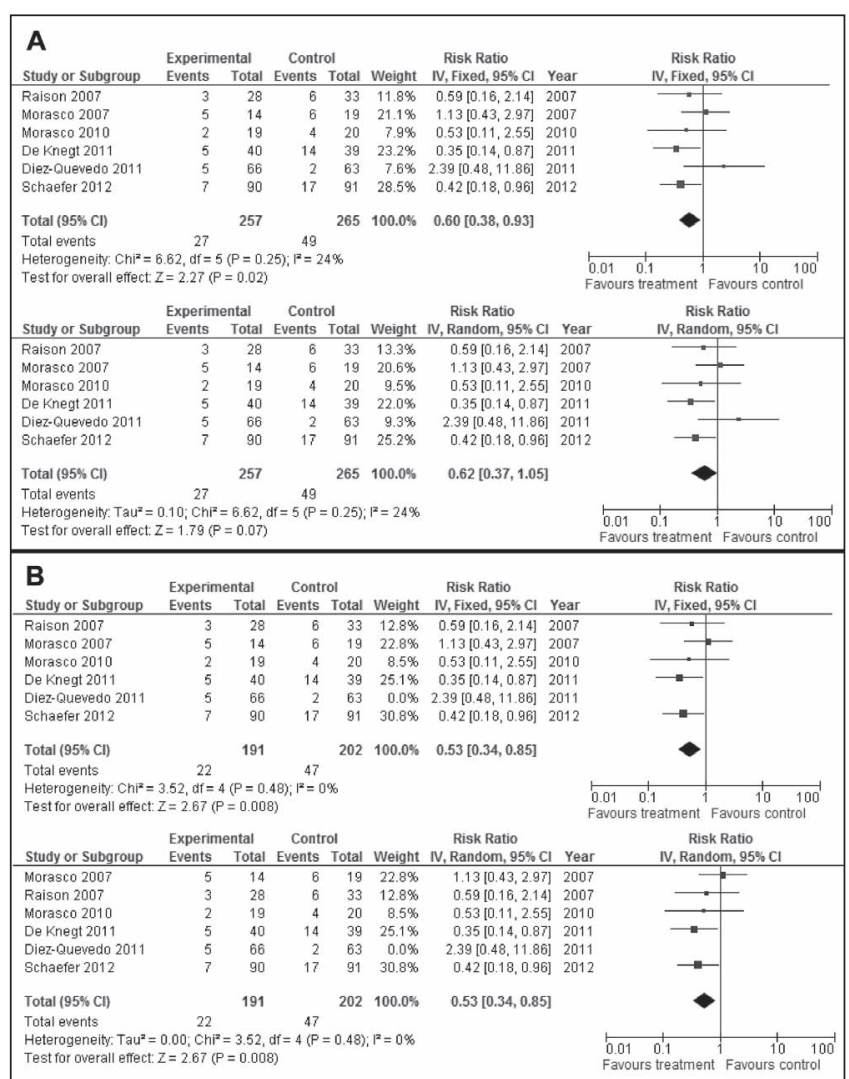

Figure 3) A Depression rate, all studies included. Forest plot of the depression risk compared between recipients of prophylactic antidepressants and the placebo group. Fixed-and random-effects analyses are represented. B Depression rate excluding directional outlier (18). Forest plot of the depression risk compared between recipients of prophylactic antidepressants and the placebo group excluding one outlying study (18). Fixedand random-effects analyses are represented

of on-treatment clinical depression using DSM-IV criteria. Clearly, the severity of these cases and/or the reduced frequency of depression in those receiving prophylactic antidepressants was insufficient to impact SVR. However, this remains an important outcome because it suggests that the burden of psychiatric side effects experienced on treatment may be partially alleviated with prophylactic antidepressants.

MADRS and BDI scores are calculated, and continuous scoring systems are used to grade an individual's depressive state at any one time and to follow it over time. Although trending in favour of benefit with antidepressants, both MADRS and BDI scores were similar between randomization groups at weeks 4, 12 and 24 of HCV antiviral therapy. It is key to note that in individual studies, a relatively high baseline MADRS score was associated with a greater protection from on-treatment depression with the use of a prophylactic antidepressant (21). Moreover, de Knegt et al (1) noted a trend toward protection from on-treatment depression in recipients of escitalopram who had a history of depressive symptoms. It would have been of value to assess these scores during the initial month of therapy because the onset of depressive mood symptoms generally begins within the first four weeks of IFN-based HCV therapy. In clinical practice, therapy is often interrupted, doses of IFN are reduced and/or antidepressant therapy with or without additional mental health care is initiated before week 12 in an effort to manage on-treatment depressive symptoms. These measures would collectively serve to diminish any difference in the MADRS and BDI scores between groups at weeks 12 and 24. Unfortunately, the level of detail required to control for these on-treatment depression management factors was not reported in the individual publications.

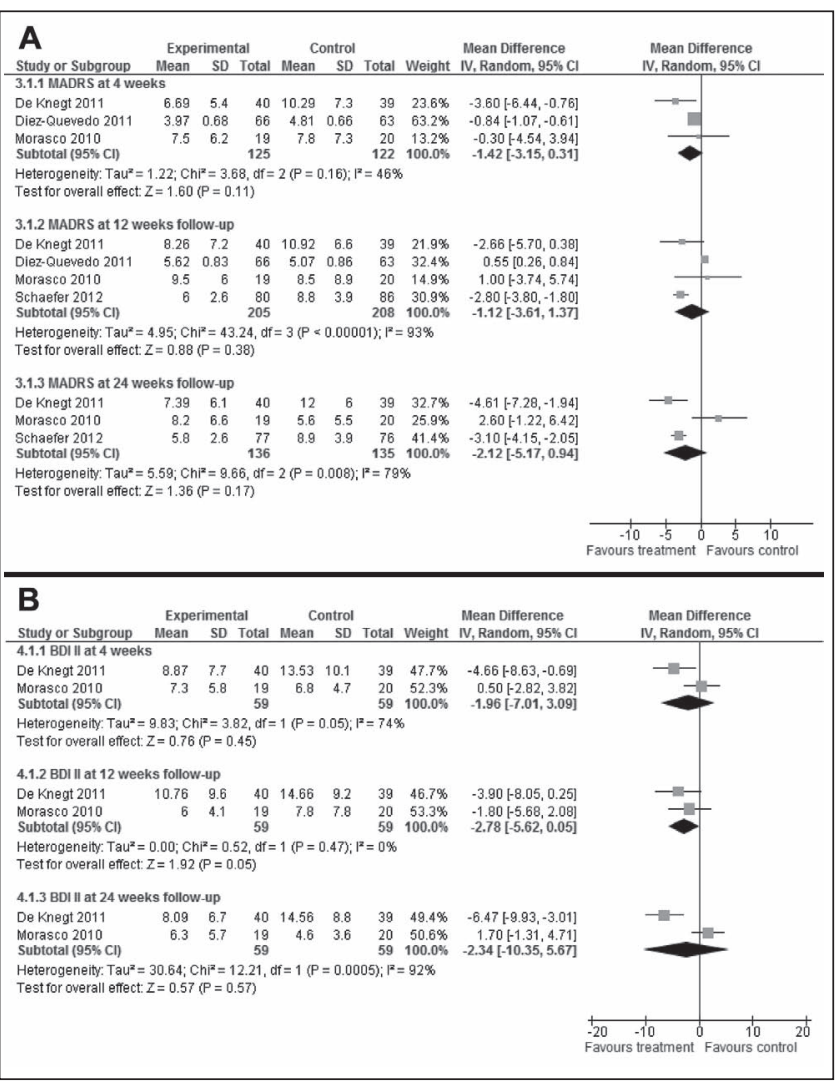

Figure 4) A Montgomery-Asberg Depression Rating Scale (MADRS) results at four, 12 and 24 weeks. Forest plot of the mean difference in MADRS scores compared between recipients of prophylactic antidepressants and placebo group at four, eight and 12 weeks. B Beck Depression Inventory (BDI) score at four, 12 and 24 weeks. Forest plot of the mean difference in BDI scores compared between recipients of prophylactic antidepressants and placebo group at four, eight and 24 weeks

Antidepressants are not without side-effect and adverse-event risk. However, there was no evidence from individual articles that the use of prophylactic antidepressants resulted in an increased symptomatic burden (19). Importantly, no suicides were reported. Raison et al (21) reported increased dizziness with paroxetine. At the very least, pill burden is increased with this practice, which is often a challenge for individuals receiving HCV antiviral therapy.

Several limitations of the present study are acknowledged. Relatively small, clinically and methodologically heterogeneous studies were evaluated. For continuous measures of effect, assumptions were made regarding normality. However, we do not believe that this altered the results. Only a small number of the many antidepressants currently in use were evaluated in the present study (ie, escitalopram, citalopram, paroxetine). It is plausible that other medications may be of greater value in preventing depression. Specifically, agents with anxiolytic and/or appetite-enhancing properties may be of overall benefit over the course of HCV treatment (30). It is noteworthy that the collective outcomes observed with any one of the three specific antidepressants assessed in the six RCTs included in our meta-analysis did not clearly differ from the overall findings (Figures 2, 3 and 4). Dose escalation was allowed in some but not all studies based on depressive symptomatology. It is possible that suboptimal doses may have been evaluated in some studies. Different IFN formulations were evaluated within and between studies. Theoretically, this could have influenced the risk of on-treatment depression and/or the response to antidepressant prophylaxis. However, several studies suggest that this is not the case (31-33). It is noteworthy that the mean maximum MADRS 
scores did not differ between nonpegylated and pegylated IFN recipients in the evaluation by Raison et al (21).

On-treatment clinical depression may be reduced with the use of pre-HCV antiviral treatment antidepressant prophylaxis. However, this practice does not improve SVR rates in those without active pretreatment depression. As such, this practice is not recommended to achieve this outcome in this population. We speculate that antidepressant prophylaxis may be of more value in those at greater risk for ontreatment depression (34). Additional study of more 'at-risk' populations would be of value.

ACKNOWLEDGEMENTS: Dr Cooper acknowledges The Ontario HIV Treatment Network for Career Scientist and The Ottawa Hospital Department of Medicine for funding support. The authors thank Dr Doug Green from The Ottawa Hospital Department of Psychiatry for his thoughtful comments during preparation of the manuscript.

\section{APPENDIX 1: SEARCH STRATEGIES}

Database: EBM Reviews - Cochrane Central Register of Controlled Trials $<$ July 2012>

Search Strategy:

July 31,2012

\section{1 exp Hepatitis C/ (1519)}

2 (hep\$ c or hcv).tw. (3424)

3 or/1-2 (3518)

4 exp Antidepressive Agents/ (8730)

5 (antidepress $\$$ or anti depress\$).tw. (5735)

6 (2-hydroxydesipramine or adinazolam or alaproclate or amineptin or aniracetam or bifemelane or clovoxamine or cyclobenzaprine or desmethyldoxepin or dibenzepin or duloxetine).mp. (500)

7 (femoxetine or flesinoxan or gepirone or hydroxymaprotilin or hypericin or indalpine or indeloxazine or L 701324 or melitracene or metapramine or milnacipran or minaprine or mirtazapine or MK 771 or nefazodone or norzimelidine or noxiptilin or O-desmethylvenlafaxine or pirlindole or progabide or reboxetine or sibutramine or sidnocarb or sulforidazine or talipexole or tianeptine or tofisopam or toloxatone or venlafaxine).mp. (2211)

8 (Benactyzine or Clorgyline or Deanol or Iproniazid or Isocarboxazid or Lithium or Moclobemide or Nialamide or Phenelzine or Pizotyline or Rolipram or Sertraline or Tranylcypromine).mp. (3557)

9 (5-hydroxytryptophan or amoxapine or bupropion or citalopram or fluoxetine or fluvoxamine or maprotiline or mianserin or paroxetine or quipazine or ritanserin or sulpiride or trazodone or tryptophan or viloxazine).mp. (8029)

10 (amitriptyline or clomipramine or desipramine or dothiepin or doxepin or imipramine or iprindole or lofepramine or nortriptyline or opipramol or protriptyline or trimipramine).mp. (5620)

11 "gamma-endorphin, des-Tyr(1)-".mp. (0)

12 or/4-11 (18383)

133 and 12 (33)

14 Chemoprevention/ (175)

15 (prophyl\$ or prevent\$).tw. (57814)

16 Secondary Prevention/ (64)

17 pc.fs. (58217)

18 or/14-17 (91430)

1913 and $18(16)$

Database: Embase Classic+Embase <1947 to 2012 July 30>, Ovid MEDLINE(R) In-Process \& Other Non-Indexed Citations and Ovid $\operatorname{MEDLINE}(\mathrm{R})<1946$ to Present>

Search Strategy:

1 hepatitis C/ (85752)

2 (hep\$ c or hcv).tw. (115886)

31 or $2(134724)$
4 exp antidepressant agent/ (289537)

5 (antidepress\$ or anti depress\$).tw. (100074)

6 (2-hydroxydesipramine or adinazolam or alaproclate or amineptin or aniracetam or bifemelane or clovoxamine or cyclobenzaprine or desmethyldoxepin or dibenzepin or duloxetine).mp. (10908)

7 (femoxetine or flesinoxan or gepirone or hydroxymaprotilin or hypericin or indalpine or indeloxazine or L 701324 or melitracene or metapramine or milnacipran or minaprine or mirtazapine or MK 771 or nefazodone or norzimelidine or noxiptilin or O-desmethylvenlafaxine or pirlindole or progabide or reboxetine or sibutramine or sidnocarb or sulforidazine or talipexole or tianeptine or tofisopam or toloxatone or venlafaxine).mp. (40745)

8 (Benactyzine or Clorgyline or Deanol or Iproniazid or Isocarboxazid or Lithium or Moclobemide or Nialamide or Phenelzine or Pizotyline or Rolipram or Sertraline or Tranylcypromine).mp. (147622)

9 (5-hydroxytryptophan or amoxapine or bupropion or citalopram or fluoxetine or fluvoxamine or maprotiline or mianserin or paroxetine or quipazine or ritanserin or sulpiride or trazodone or tryptophan or viloxazine).mp. (221473) 10 (amitriptyline or clomipramine or desipramine or dothiepin or doxepin or imipramine or iprindole or lofepramine or nortriptyline or opipramol or protriptyline or trimipramine).mp. (107989)

11 "gamma-endorphin, des-Tyr(1)-".mp. (119)

12 or/4-11 (581569)

133 and 12 (1665)

14 prophylaxis/ or prevention/ (226155)

15 (prophyl\$ or prevent\$).tw. (2026595)

16 pc.fs. (1775475)

$17 \quad 14$ or 15 or $16(3334178)$

$18 \quad 13$ and 17 (423)

19 remove duplicates from 18 (382)

2019 use emczd (373)

21 exp Hepatitis C/ (98369)

22 (hep\$ c or hcv).tw. (115886)

23 or/21-22 (136052)

24 exp Antidepressive Agents/ (400569)

25 (antidepress $\$$ or anti depress\$).tw. (100074)

26 (2-hydroxydesipramine or adinazolam or alaproclate or amineptin or aniracetam or bifemelane or clovoxamine or cyclobenzaprine or desmethyldoxepin or dibenzepin or duloxetine).mp. (10908)

27 (femoxetine or flesinoxan or gepirone or hydroxymaprotilin or hypericin or indalpine or indeloxazine or L 701324 or melitracene or metapramine or milnacipran or minaprine or mirtazapine or MK 771 or nefazodone or norzimelidine or noxiptilin or O-desmethylvenlafaxine or pirlindole or progabide or reboxetine or sibutramine or sidnocarb or sulforidazine or talipexole or tianeptine or tofisopam or toloxatone or venlafaxine).mp. (40745)

28 (Benactyzine or Clorgyline or Deanol or Iproniazid or Isocarboxazid or Lithium or Moclobemide or Nialamide or Phenelzine or Pizotyline or Rolipram or Sertraline or Tranylcypromine).mp. (147622)

29 (5-hydroxytryptophan or amoxapine or bupropion or citalopram or fluoxetine or fluvoxamine or maprotiline or mianserin or paroxetine or quipazine or ritanserin or sulpiride or trazodone or tryptophan or viloxazine).mp. (221473)

30 (amitriptyline or clomipramine or desipramine or dothiepin or doxepin or imipramine or iprindole or lofepramine or nortriptyline or opipramol or protriptyline or trimipramine).mp. (107989)

$\begin{array}{ll}31 & \text { "gamma-endorphin, des-Tyr(1)-".mp. (119) } \\ 32 & \text { or/24-31 (591986) } \\ 33 & 23 \text { and } 32 \text { (1698) } \\ 34 & \text { Chemoprevention/ (18441) } \\ 35 & \text { (prophyl\$ or prevent\$).tw. (2026595) } \\ 36 & \text { Secondary Prevention/ (13291) } \\ 37 & \text { pc.fs. (1775475) } \\ 38 & \text { or/34-37 (3233523) } \\ 39 & 33 \text { and 38 (425) } \\ 40 & 39 \text { use prmz (57) } \\ 41 & \text { remove duplicates from } 40(57) \\ 42 & 20 \text { or 41 (430) } \\ 43 & \text { remove duplicates from } 42(384)\end{array}$




\section{APPENDIX 2}

\section{Risk of bias assessment}

\begin{tabular}{|c|c|c|c|c|c|c|}
\hline \multirow[b]{2}{*}{ Criterion } & \multicolumn{6}{|c|}{ Author (reference), year } \\
\hline & $\begin{array}{l}\text { Raison et al } \\
\text { (21), } 2007\end{array}$ & $\begin{array}{l}\text { Morasco et al } \\
(20), 2007\end{array}$ & $\begin{array}{l}\text { Morasco et al } \\
\text { (19), } 2010\end{array}$ & $\begin{array}{l}\text { Diez-Quevedo } \\
\text { et al (18), } 2011\end{array}$ & $\begin{array}{c}\text { De Knegt } \\
\text { et al (1), } 2011\end{array}$ & $\begin{array}{l}\text { Schaefer et al } \\
\text { (22), } 2012\end{array}$ \\
\hline Adequate sequence generation? & Low & High & Low & Low & Low & Low \\
\hline Allocation concealment? & Unclear & Low & Low & Low & Low & Low \\
\hline Blinding of participants and personnel? & Low & Low & Low & Low & Low & Low \\
\hline Blinding of outcome assessment? & Low & Low & Low & Low & Low & Low \\
\hline Incomplete outcome data addressed? & High & Low & Unclear & Low & Low & Low \\
\hline Free of selective reporting? & Low & Low & Low & Low & Low & Low \\
\hline Free of other bias? & Low & High & Low & Low & High & High \\
\hline
\end{tabular}

\section{REFERENCES}

1. de Knegt RJ, Bezemer G, Van Gool AR, et al. Randomised clinical trial: Escitalopram for the prevention of psychiatric adverse events during treatment with peginterferon-alfa-2a and ribavirin for chronic hepatitis C. Aliment Pharmacol Ther 2011;34:1306-17.

2. Dienstag JL, McHutchison JG. American Gastroenterological Association technical review on the management of hepatitis C. Gastroenterology 2006;130:231-64.

3. Deutsch M, Hadziyannis SJ. Old and emerging therapies in chronic hepatitis C: An update. J Viral Hepat 2008;15:2-11.

4. Manns MP, McHutchison JG, Gordon SC, et al. Peginterferon alfa$2 \mathrm{~b}$ plus ribavirin compared with interferon alfa- $2 \mathrm{~b}$ plus ribavirin for initial treatment of chronic hepatitis C: A randomised trial. Lancet 2001;358:958-65.

5. Fried MW, Shiffman ML, Reddy KR, et al. Peginterferon alfa-2a plus ribavirin for chronic hepatitis $C$ virus infection. N Engl J Med 2002;347:975-82.

6. Kraus MR, Schafer A, Schottker K, et al. Therapy of interferoninduced depression in chronic hepatitis $\mathrm{C}$ with citalopram: A randomised, double-blind, placebo-controlled study. Gut 2008;57:531-6.

7. Dieperink E, Willenbring M, Ho SB. Neuropsychiatric symptoms associated with hepatitis $\mathrm{C}$ and interferon alpha: $\mathrm{A}$ review. Am J Psychiatry 2000;157:867-76.

8. Schaefer M, Engelbrecht MA, Gut O, et al. Interferon alpha (IFNalpha) and psychiatric syndromes: A review. Prog Neuropsychopharmacol Biol Psychiatry 2002;26:731-46.

9. Constant A, Castera L, Dantzer R, et al. Mood alterations during interferon-alfa therapy in patients with chronic hepatitis $C$ : Evidence for an overlap between manic/hypomanic and depressive symptoms. J Clin Psychiatry 2005;66:1050-7.

10. Hauser P, Khosla J, Aurora H, et al. A prospective study of the incidence and open-label treatment of interferon-induced major depressive disorder in patients with hepatitis C. Mol Psychiatry 2002;7:942-7.

11. Leutscher PD, Lagging M, Buhl MR, et al. Evaluation of depression as a risk factor for treatment failure in chronic hepatitis $\mathrm{C}$. Hepatology 2010;52:430-5.

12. Loftis JM, Hauser P. The phenomenology and treatment of interferon-induced depression. J Affect Disord 2004;82:175-90.

13. Loftis JM, Matthews AM, Hauser P. Psychiatric and substance use disorders in individuals with hepatitis C: Epidemiology and management. Drugs 2006;66:155-74.

14. Hauser P. Neuropsychiatric side effects of HCV therapy and their treatment: Focus on IFN alpha-induced depression. Gastroenterol Clin North Am 2004;33(1 Suppl):S35-50.

15. Horsmans Y. Interferon-induced depression in chronic hepatitis C. J Antimicrob Chemother 2006;58:711-3.

16. Asnis GM, De La Garza R II. Interferon-induced depression in chronic hepatitis C: A review of its prevalence, risk factors, biology, and treatment approaches. J Clin Gastroenterol 2006;40:322-35.

17. Liu SS, Schneekloth TD, Talwalkar JA, et al. Impact of depressive symptoms and their treatment on completing antiviral treatment in patients with chronic hepatitis C. J Clin Gastroenterol 2010;44:e178-85.

18. Diez-Quevedo C, Masnou H, Planas R, et al. Prophylactic treatment with escitalopram of pegylated interferon alfa-2a-induced depression in hepatitis C: A 12-week, randomized, double-blind, placebo-controlled trial. J Clin Psychiatry 2011;72:522-8.

19. Morasco BJ, Loftis JM, Indest DW, et al. Prophylactic antidepressant treatment in patients with hepatitis $C$ on antiviral therapy: A double-blind, placebo-controlled trial. Psychosomatics 2010;51:401-8.

20. Morasco BJ, Rifai MA, Loftis JM, Indest DW, Moles JK, Hauser P. A randomized trial of paroxetine to prevent interferon-alphainduced depression in patients with hepatitis C. J Affect Disord 2007;103:83-90.

21. Raison CL, Woolwine BJ, Demetrashvili MF, et al. Paroxetine for prevention of depressive symptoms induced by interferon-alpha and ribavirin for hepatitis C. Alimentary Pharmacol Ther 2007;25:1163-74.

22. Schaefer M, Sarkar R, Knop V, et al. Escitalopram for the prevention of peginterferon-alpha2a-associated depression in hepatitis $C$ virus-infected patients without previous psychiatric disease: A randomized trial. Ann Intern Med 2012;157:94-103.

23. Beck A, Steer R, Brown G. Beck Depression Inventory Manual. 2nd edn. New York: Psychological Corp, 1996.

24. Dieperink E, Ho SB, Thuras P, Willenbring ML. A prospective study of neuropsychiatric symptoms associated with interferonalpha-2b and ribavirin therapy for patients with chronic hepatitis C. Psychosomatics 2003;44:104-12.

25. Musselman DL, Lawson DH, Gumnick JF, et al. Paroxetine for the prevention of depression induced by high-dose interferon alfa. N Engl J Med 2001;344:961-6.

26. Higgins JP, Altman DG, Gotzsche PC, et al. The Cochrane Collaboration's tool for assessing risk of bias in randomised trials. BMJ 2011;343:d5928.

27. DerSimonian R, Laird N. Meta-analysis in clinical trials. Control Clin Trials 1986;7:177-88.

28. Deeks JJ, Higgins JP, Altman DG. Analysing data and undertaking meta analyses. In: Higgins JP, Green S, eds. Cochrane Handbook for Systematic Reviews of Interventions: Cochrane Book Series. London: John Wiley \& Sons, Inc; 2008:243-96.

29. Higgins JP, Thompson SG. Quantifying heterogeneity in a metaanalysis. Stat Med 2002;21:1539-58.

30. Baraldi S, Hepgul N, Mondelli V, Pariante CM. Symptomatic treatment of interferon-alpha-induced depression in hepatitis $\mathrm{C}$ : A systematic review. J Clin Psychopharmacol 2012;32:531-43.

31. Fumaz CR, Munoz-Moreno JA, Ballesteros AL, et al. Influence of the type of pegylated interferon on the onset of depressive and neuropsychiatric symptoms in HIV-HCV coinfected patients. AIDS Care 2007;19:138-45.

32. Kraus MR, Schafer A, Csef H, Scheurlen M. Psychiatric side effects of pegylated interferon alfa-2b as compared to conventional interferon alfa-2b in patients with chronic hepatitis $\mathrm{C}$. World J Gastroenterol 2005;11:1769-74.

33. Reddy KR, Wright TL, Pockros PJ, , et al. Efficacy and safety of pegylated $(40-\mathrm{kd})$ interferon alpha-2a compared with interferon alpha-2a in noncirrhotic patients with chronic hepatitis $C$. Hepatology 2001;33:433-8.

34. Schaefer M, Schwaiger M, Garkisch AS, et al. Prevention of interferon-alpha associated depression in psychiatric risk patients with chronic hepatitis C. J Hepatol 2005;42:793-8. 


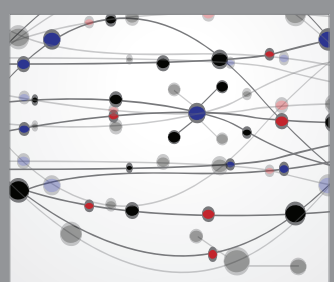

The Scientific World Journal
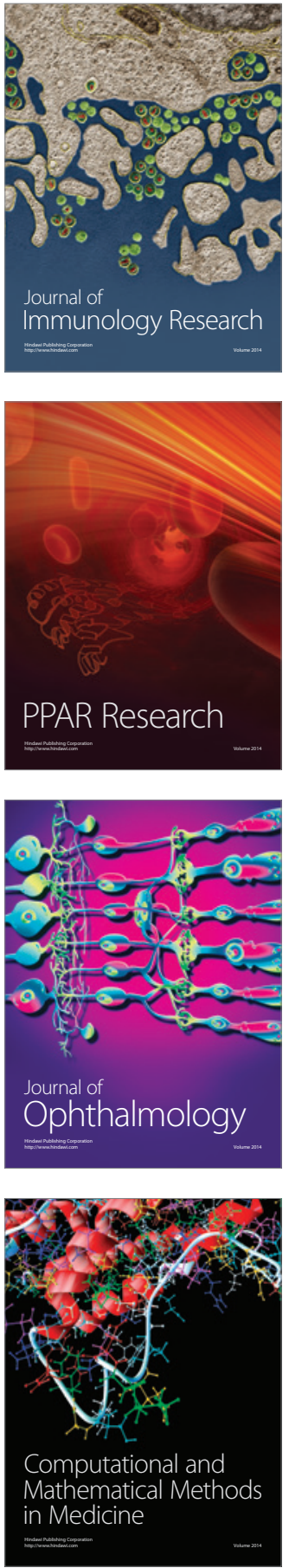

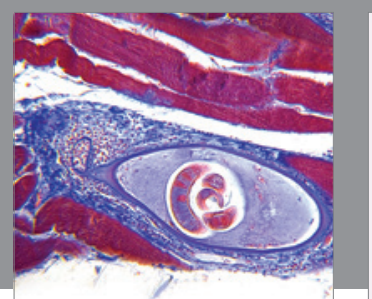

Gastroenterology Research and Practice

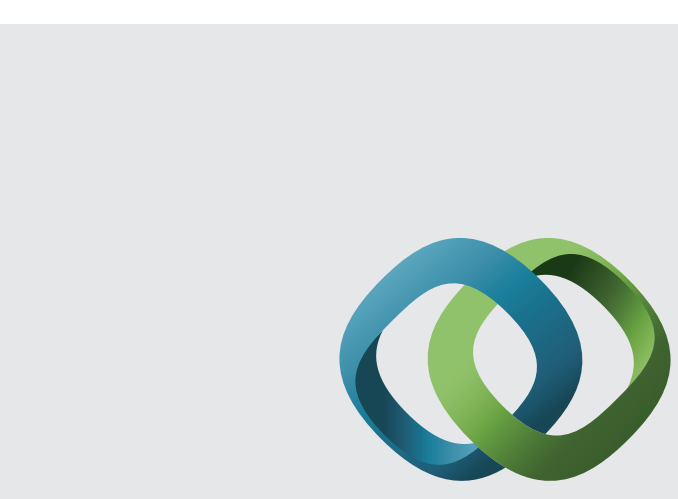

\section{Hindawi}

Submit your manuscripts at

http://www.hindawi.com
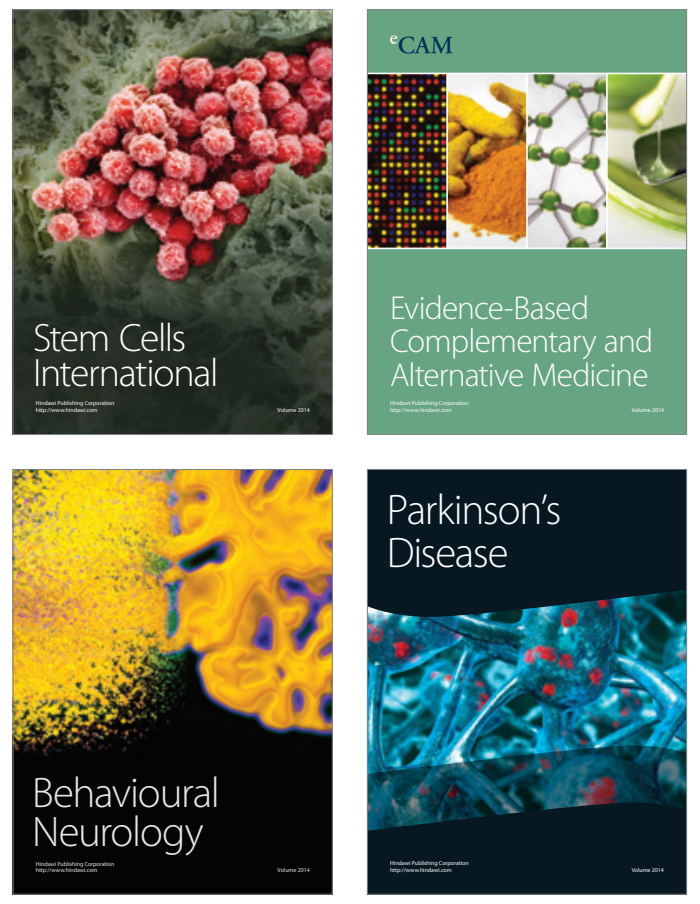
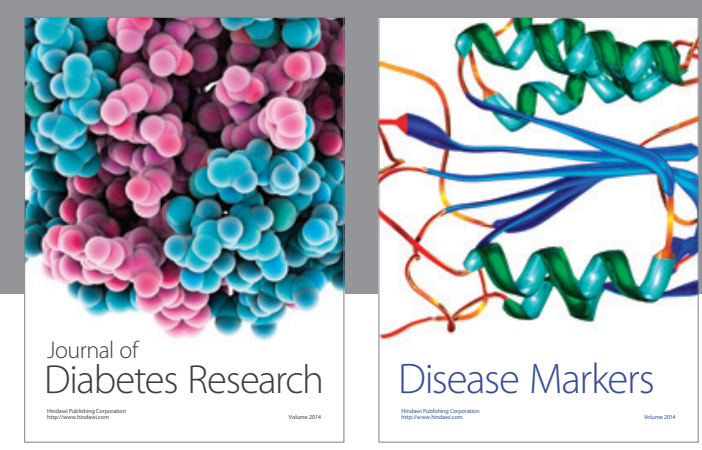

Disease Markers
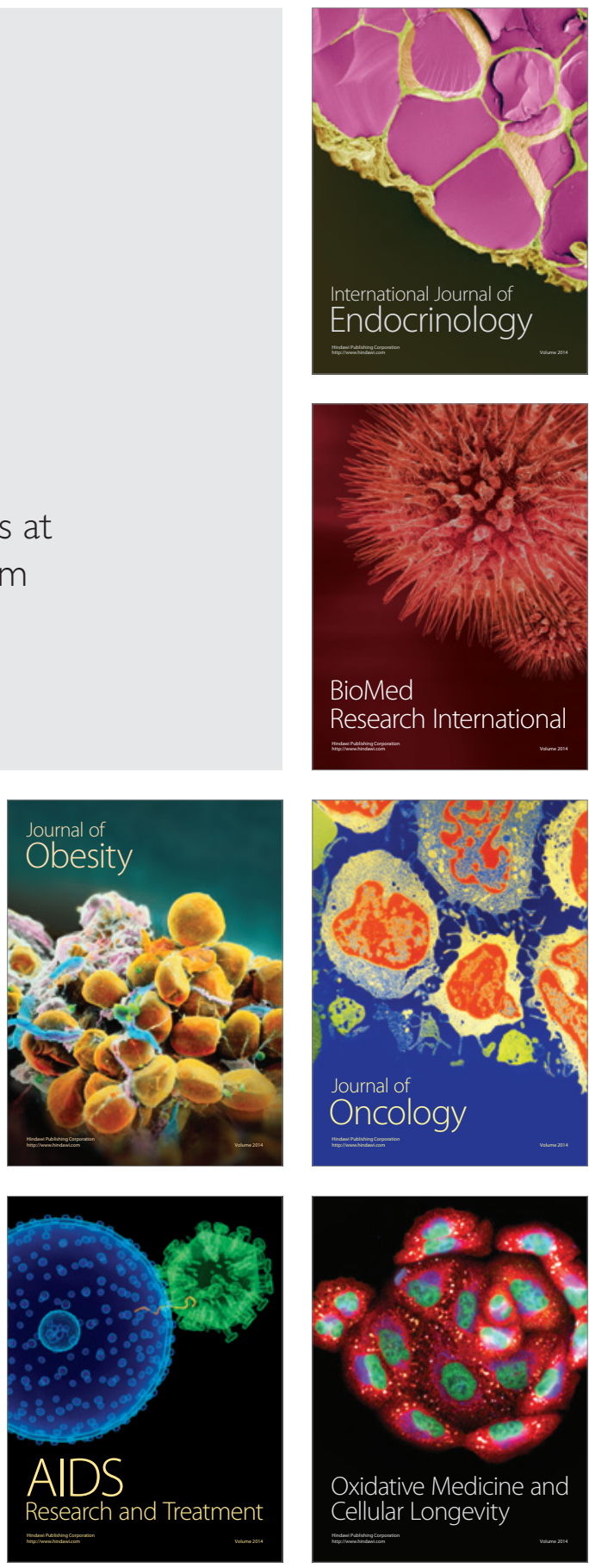